Protocol

\title{
Enrichment and Detection of Antigen-Binding B Cells for Mass Cytometry
}

\author{
Zachary C. Stensland ${ }^{1}$ and Mia J. Smith ${ }^{1,2, *}$ \\ 1 Barbara Davis Center for Diabetes, Department of Pediatrics, University of Colorado School of Medicine, \\ Aurora, CO 80045, USA; zachary.stensland@cuanschutz.edu \\ 2 Department of Immunology and Microbiology, University of Colorado School of Medicine, \\ Aurora, CO 80045, USA \\ * Correspondence: mia.smith@cuanschutz.edu
}

check for updates

Citation: Stensland, Z.C.; Smith, M.J Enrichment and Detection of Antigen-Binding B Cells for Mass Cytometry. Magnetochemistry 2021, 7, 92. https://doi.org/10.3390/ magnetochemistry7070092

Academic Editor: Marie Frenea-Robin

Received: 3 May 2021

Accepted: 21 June 2021

Published: 23 June 2021

Publisher's Note: MDPI stays neutral with regard to jurisdictional claims in published maps and institutional affiliations.

Copyright: (c) 2021 by the authors. Licensee MDPI, Basel, Switzerland. This article is an open access article distributed under the terms and conditions of the Creative Commons Attribution (CC BY) license (https:// creativecommons.org/licenses/by/ $4.0 /)$.

\begin{abstract}
Over the years, various techniques have been utilized to study the function and phenotype of antigen-binding B cells in the primary repertoire following immunization, infection, and development of autoimmunity. Due to the low frequency of antigen-reactive B cells $(<0.05 \%$ of lymphocytes) in the periphery, preliminary enrichment of cells is necessary to achieve sufficient numbers for statistically sound characterization, especially when downstream analytic platform use, e.g., CyTOF, is low throughput. We previously described a method to detect and enrich antigenreactive $\mathrm{B}$ cells from peripheral blood and tissues using biotinylated antigens in conjunction with magnetic nanoparticles, preparative to a downstream analysis by ELISPOT and flow cytometry. While mass cytometry (CyTOF) enables high dimensional immunophenotyping of over 40 unique parameters on a single-cell level, its low throughput compared to flow cytometry and requirement for removal of metal contaminants, such as nanoparticles, made it particularly unsuitable for studies of rare cells in a mixed population. Here we describe a novel CyTOF-compatible approach for multiplexed enrichment of antigen-reactive B cells, e.g., insulin and tetanus toxoid, using cleavable magnetic nanoparticles. This method allows improved monitoring of the phenotype and function of antigen-reactive B cells during the development of disease or after immunization while minimizing the amount of sample and run times needed.
\end{abstract}

Keywords: CyTOF; mass cytometry; magnetic enrichment; antigen-specific B cells; antigen-binding B cells; antigen-reactive B cells; B lymphocytes; B cells

\section{Introduction}

Effective study of the biology of antigen-reactive B cells before and during the development of the immune responses and their perturbation during disease development requires examination of $B$ cells on an antigen-specific level. Previous methods to identify antigen-reactive B cells have included assays such as limiting dilution, ELISPOT, and most commonly flow cytometry [1-9]. Previously, we developed a method to identify and enrich rare antigen-reactive $\mathrm{B}$ cells from polyclonal repertoires using biotinylated antigen and magnetic nanoparticles, which is compatible with a variety of downstream assays [10]. Using this method, we studied changes in the phenotype of self-reactive B cells during the development of type 1 diabetes and autoimmune thyroid disease, as well as foreign-reactive (e.g., tetanus) B cells prior to and after vaccination [10-14]. While our previous method has been instrumental in better understanding phenotypic changes in antigen-reactive B cells during the course of the disease and after vaccination, it is limited by the relatively low number of parameters able to be assayed simultaneously by flow cytometry (even with spectral flow cytometry).

Mass cytometry, or CyTOF (Fluidigm), is a technology that combines flow cytometry and mass spectrometry in which antibodies or other ligands used to label cells are 
conjugated to heavy metal isotopes that are identified using time-of-flight mass spectrometry $[15,16]$. Some advantages of mass cytometry over traditional fluorescence-based flow cytometry are that currently as many as 50 individual parameters can be analyzed simultaneously with minimal spillover between output signals and little need for compensation or unmixing. Like flow cytometry, mass cytometry can be used to study the phenotypic and functional properties of various cell types thanks to its compatibility with pre-existing methods such as immunophenotyping, intracellular staining, and phosphoflow. Moreover, it was recently demonstrated that mass cytometry is comparable to flow cytometry in terms of quantification of cell lineages and markers of activation, function, and exhaustion using low numbers of human PBMCs [17].

Hence, in order to take advantage of the high-parameter single-cell immunophenotyping capability of mass cytometry, we developed a method to enable enrichment and identification of antigen-binding B cells from human PBMCs that is compatible with mass cytometry. During the initial development of this method, we first attempted to identify antigen-reactive $B$ cells using directly metal labeled antigens that bind to the $B$ cell receptor (BCR) followed by CyTOF analysis, without intervening enrichment. However, we found that due to the low throughput of mass cytometry statistically sound characterization of antigen-reactive B cells using mass cytometry necessitates prior enrichment of the cells of interest. However, unlike flow cytometry, for this analysis, magnetic nanoparticles must be removed from enriched cells because they contain barium and other heavy metals that may foul the spectrometer. This can be accomplished using "cleavable" beads, as previously described [18]. Hence, in our method, we utilize commercially available cleavable antibiotin and anti-FITC magnetic beads to enrich our antigen-reactive B cells of interest. In addition, after careful optimization, we have modified our previous method to enable the identification and tracking of more than one type of antigen-reactive B cell within the same sample. Importantly, while successful identification of antigen-specific T cells has been previously shown using mass cytometry [18-20], to our knowledge, this is the first study to demonstrate the ability to characterize antigen-reactive B cells using this tool. Moreover, previous studies to analyze antigen-specific T cells using mass cytometry have either, (1) used metal labeled tetramers to detect antigen-specific T cells without prior enrichment, resulting in very few cells of interest for analysis, or (2) enriched for antigen-reactive T cells based on upregulation of activation markers (e.g., CD69) after stimulation with antigen in vitro. Hence, our method is unique in that it combines detection using the antigen of interest as bait with enrichment using cleavable beads, resulting in a more pure population for analysis.

Here we demonstrate simultaneous enrichment of insulin-binding B cells and tetanustoxoid-binding B cells from the peripheral blood of healthy individuals using mass cytometry. The basic steps for our protocol are as follows: first, PBMCs are incubated with a live-dead marker [21], followed by staining with FITC conjugated tetanus-toxoid and biotinylated insulin. Cells are fixed, followed by enrichment of antigen-binding B cells using cleavable anti-biotin and anti-FITC magnetic beads and LS MACS columns (Miltenyi Biotech, Bergisch Gladbach, Germany). The magnetic beads are then cleaved away from labeled cells. After washing, the enriched cells are stained with metal-labeled antibodies to various cell surface markers, as well as metal labeled anti-FITC and anti-biotin antibodies to identify tetanus and insulin-binding B cells, respectively. Finally, enriched cells are analyzed by the mass cytometer. A schematic for this method is represented in Figure 1 and the materials needed are listed in Table 1 . We conclude with a discussion of the various limitations of the method and important considerations that should be taken into account when applying the method. 


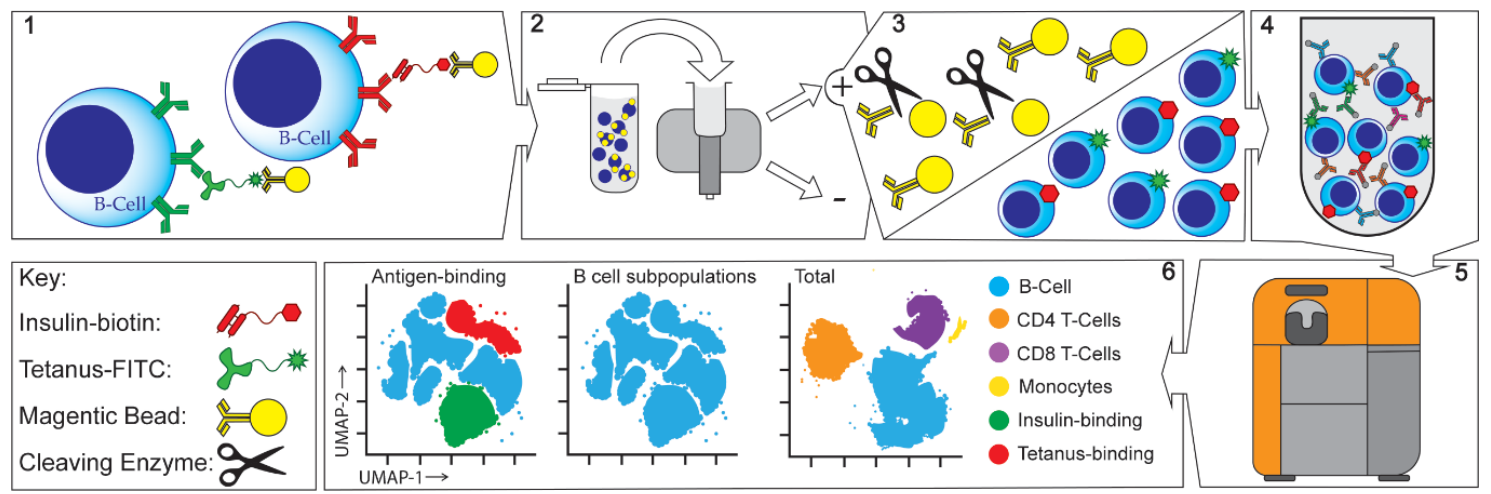

Figure 1. Schematic for magnetic enrichment of antigen-reactive B cells. 1. Human PBMCs are incubated with properly titrated amounts of biotin and FITC-labeled antigens. Cells are then incubated with a combination of cleavable anti-biotin and anti-FITC magnetic beads. 2. Washed cells are then added to a magnetic column and separated into depleted and enriched fractions. 3. Magnetic microbeads are cleaved off and washed away. 4 . Cells are then incubated with an antibody cocktail containing various metal labeled antibodies. 5. Cells are analyzed on a mass cytometer. 6. Data analysis is performed using a combination of manual gating and dimensionality reduction and clustering algorithms.

Table 1. Materials.

\begin{tabular}{|c|c|c|c|}
\hline Name: & Company: & Catalog Number: & Comments: \\
\hline LS Columns & Miltenyi Biotech & $130-042-401$ & \\
\hline Anti-Biotin Multi-sort Kit & Miltenyi Biotech & $130-091-256$ & \\
\hline Anti-FITC Multi-sort Kit & Miltenyi Biotech & $130-058-701$ & \\
\hline MACS manual separators & Miltenyi Biotech & Variable & \\
\hline FcR Blocking Reagent human & Miltenyi Biotech & 130-059-901 & \\
\hline Tetanus-toxoid & Colorado Serum Company & & $\begin{array}{l}\text { Unadjuvanted with no carrier } \\
\text { proteins present }\end{array}$ \\
\hline Human Insulin Biotinylated & Eagle Biosciences & INS30-G100 & \\
\hline $\begin{array}{l}\text { PBS without calcium } \\
\text { and magnesium }\end{array}$ & & & $\begin{array}{l}\text { No contact with autoclaved } \\
\text { bottles or beakers or dish soap }\end{array}$ \\
\hline Ficoll-Paque PLUS & VWR International & 95021-205 & \\
\hline $\begin{array}{l}\text { Pierce }^{\mathrm{TM}} \text { FITC } \\
\text { Antibody Labeling Kit }\end{array}$ & ThermoFisher Scientific & 53027 & \\
\hline $\begin{array}{l}\text { Pierce }^{\mathrm{TM}} 16 \% \text { Formaldehyde }(w / v) \text {, } \\
\text { Methanol-free }\end{array}$ & ThermoFisher Scientific & 28908 & Dilute to $1.6 \%$ with CSM. \\
\hline $\begin{array}{l}\text { Whole blood in heparinized } \\
\text { collection tubes }\end{array}$ & & & $\begin{array}{l}\text { We typically use at least } 30 \mathrm{~mL} \\
\text { of whole blood to enrich our } \\
\text { cells of interest }\end{array}$ \\
\hline $\begin{array}{l}\text { Cell Staining Media (CSM) } \\
(\text { PBS }+0.5 \% \text { BSA }+2 \text { mM EDTA) }\end{array}$ & & & $\begin{array}{l}\text { No contact with autoclaved } \\
\text { bottles or beakers or dish soap }\end{array}$ \\
\hline \multicolumn{4}{|l|}{$50 \mathrm{~mL}$ conical Tubes } \\
\hline \multicolumn{4}{|l|}{$15 \mathrm{~mL}$ conical Tubes } \\
\hline \multicolumn{4}{|l|}{$1.5 \mathrm{~mL}$ Eppendorf tubes } \\
\hline \multicolumn{4}{|l|}{$\begin{array}{l}\text { MAXPAR-labeled antibodies } \\
\text { of interest }\end{array}$} \\
\hline 160Gd-anti-FITC antibody & Fluidigm & 3160011B & \\
\hline 170Er-anti-biotin antibody & Fluidigm & 3170003B & \\
\hline Cisplatin live/dead & Fluidigm & 201195 & Stock at $25 \mathrm{mM}$ \\
\hline DNA Intercalator & Fluidigm & 201192B & $500 \mathrm{uM}$ stock \\
\hline
\end{tabular}




\section{Materials and Methods}

\section{Protocol:}

1. Isolation of PBMC's from Whole Blood

1. Collect $30-50 \mathrm{~mL}$ of heparinized blood collection tubes

2. Dilute heparinized blood 1:1 with sterile, room temperature magnesium and calcium-free phosphate-buffered saline (PBS).

3. In a $50 \mathrm{~mL}$ conical tube, add $10-15 \mathrm{~mL}$ of room temperature Ficoll-Paque PLUS.

4. Carefully layer $30-35 \mathrm{~mL}$ of the diluted blood on the top of the Ficoll-Paque at the lowest speed setting, being careful not to mix the two.

5. Centrifuge at $400 \times g$ for $30 \mathrm{~min}$ at room temperature with the brake turned off.

6. Using a serological pipette remove the mononuclear layer (buffy coat) and transfer to a clean $50 \mathrm{~mL}$ conical. Add at least 3 times the volume of PBS to the cell suspension.

7. Centrifuge cells at $400 \times g$ for $10 \mathrm{~min}$ at room temperature with the brake on.

8. Remove supernatant and resuspend cells in $10 \mathrm{~mL}$ PBS. Count cells and determine viability using a hemocytometer or automated cell counter.

9. Adjust cell concentration to $3 \times 10^{7}$ cells $/ 1 \mathrm{~mL}$ CSM buffer and place on ice until ready to begin processing.

2. Viability Dye

1. Centrifuge $30 \times 10^{6}$ cells at $400 \times g$ for $5 \mathrm{~min}$ at room temperature and aspirate supernatant.

2. Wash cells $1 \times$ with $1 \mathrm{~mL}$ sterile PBS

i. Do not use any solutions with serum or protein content until after cisplatin incubation.

3. Spin down at $400 \times g$ for $5 \mathrm{~min}$ at room temperature and aspirate supernatant.

4. Resuspend cells in serum-free RPMI at $3 \times 10^{6}$ cells per $1 \mathrm{~mL}$ RPMI.

5. Add $1 \mathrm{uL}$ ( $25 \mathrm{mM}$ stock) of Cisplatin per $1 \mathrm{~mL}$ of serum-free RPMI and vortex samples briefly to mix thoroughly ( $25 \mathrm{uM}$ final concentration).

6. Incubate for $1 \mathrm{~min}$ at RT before quenching solution with $2 \mathrm{~mL} \mathrm{CSM}$ or complete RPMI per $1 \mathrm{~mL}$ of cisplatin-cell solution.

i. It is necessary to quench with a solution that contains protein to bind extraneous cisplatin

7. Spin cells at $400 \times g$ for $5 \mathrm{~min}$ at room temperature and aspirate supernatant.

3. Enrichment of antigen-reactive B cells

1. Wash cells once with $1 \mathrm{~mL} \mathrm{CSM}$. Centrifuge cells at $400 \times g$ for $5 \mathrm{~min}$ and aspirate supernatant.

2. Resuspend cells in $25 \mathrm{uL}$ Fc Block and allow them to bind for 5 min on ice. Do not wash off.

3. Add $1 \mathrm{~mL} \mathrm{CSM}$ to cells before adding antigen(s) at their pre-determined amount. Vortex briefly to mix and incubate on ice for $15 \mathrm{~min}$ in the dark.

i. $\quad$ Note: Biotinylated and FITC conjugated antigens should be titrated to determine the optimal concentrations needed to ensure detection and separation of binding cells from non-specific bystander cells. Typically, a good starting concentration is between $0.025 \mathrm{ug}$ and $1 \mathrm{ug}$ per $1 \times 10^{6}$ cells. (See Smith et al. for detailed protocol [10])

ii. Eagle-Insulin-biotin $(0.4 \mathrm{mg} / \mathrm{mL}$ stock, commercially available): Use $0.035 \mathrm{ug} / 1 \times 10^{6}$ cells $=1.05 \mathrm{ug} / 30 \times 10^{6}$ cells $=2.63 \mathrm{uL}$

iii. Tetanus-Toxoid-FITC ( $2 \mathrm{mg} / \mathrm{mL}$ stock, FITC labeled according to manufacturer's instructions): Use $1 \mathrm{ug} / 1 \times 10^{6}$ cells $=30 \mathrm{ug} / 30 \times 10^{6}$ cells. $=15 \mathrm{uL}$

4. Wash cells $2 \times$ with $1 \mathrm{~mL}$ cold CSM at $400 \times g$ for $5 \mathrm{~min}$ before aspirating supernatant. 
5. During centrifugation prepare $1.6 \%$ PFA solution using the following steps:

i. Break open an unopened ampule of $16 \%$ paraformaldehyde and sterile filter using a $0.45 \mu \mathrm{m}$ syringe filter into a $15 \mathrm{~mL}$ conical tube.

ii. Dilute to $1.6 \%$ PFA by adding $9 \mathrm{~mL}$ of CSM to the $1 \mathrm{~mL}$ of $16 \%$ PFA. Wrap conical tightly in tin foil to avoid light exposure. Keep $\sim 1$ week.

iii. It is important to use fresh PFA, as improperly fixed cells can lyse after the addition of MilliQ water.

6. Aspirate supernatant and resuspend the cells in $1 \mathrm{~mL} \mathrm{1.6 \%} \mathrm{PFA.} \mathrm{Allow} \mathrm{for}$ staining in dark at room temperature for $5 \mathrm{~min}$.

7. Wash cells $2 \times$ with $1 \mathrm{~mL}$ cold CSM at $400 \times g$ for $5 \mathrm{~min}$ before aspirating supernatant.

8. Resuspend cells in the following:

i. $\quad 60 \mathrm{uL}$ MACS cleavable anti-biotin beads $\left(20 \mathrm{uL} / 10^{7}\right.$ cells $)+30 \mathrm{uL}$ MACS cleavable anti-FITC beads $\left(10 \mathrm{uL} / 10^{7}\right.$ cells) $+210 \mathrm{uL}$ CSM (final volume should be $100 \mathrm{uL} / 10^{7}$ cells)

1. The amount of anti-biotin and anti-FITC beads to add should be determined beforehand using the manufacturer's instructions.

9. Vortex briefly to mix and incubate cells for $15 \mathrm{~min}$ at $4{ }^{\circ} \mathrm{C}$ in the dark.

10. Add $1 \mathrm{~mL}$ cold CSM to the mixture and centrifuge at $400 \times g$ for $5 \mathrm{~min}$. Aspirate the supernatant.

11. During this time, place MACS LS column on MACS magnet. Allow $3 \mathrm{~mL}$ of cold CSM to flow through the column to prime the column.

12. Resuspend cells in $1 \mathrm{~mL}$ CSM and add to LS column. Collect "depleted" flow through in $15 \mathrm{~mL}$ conical tube.

13. Wash unbound cells from the column by adding $3 \mathrm{~mL}$ cold CSM on top of the LS column and allowing the volume to completely flow through the column into the depleted fraction. Repeat with another $3 \mathrm{~mL}$ of cold CSM.

14. Place a new $15 \mathrm{~mL}$ conical tube labeled "enriched" under the LS column and fill with $6 \mathrm{~mL}$ of cold CSM. Plunge the CSM through the column using equal steady pressure to collect cells held in the magnetic field using the provided plunger.

15. Centrifuge both depleted and enriched fractions of cells at $400 \times g$ for $10 \mathrm{~min}$ at $4{ }^{\circ} \mathrm{C}$.

16. Resuspend the depleted fraction in an appropriate volume to re-count. Resuspend $2-3 \times 10^{6}$ cells from the depleted fraction in $1 \mathrm{~mL}$ cold CSM in a $1.5 \mathrm{~mL}$ Eppendorf tube. Resuspend the enriched fraction in $1 \mathrm{~mL}$ cold CSM in a $1.5 \mathrm{~mL}$ Eppendorf tube (we assume the number of cells in our enriched fraction is $\leq 1$ million cells).

17. Add $20 \mathrm{uL}$ multi-sort release agent per $1 \mathrm{~mL}$ cell suspension. Vortex briefly to mix and incubate for $10 \mathrm{~min}$ at $4{ }^{\circ} \mathrm{C}$ in the dark.

18. Wash cells by adding 9-10 $\mathrm{mL}$ cold CSM to the cell suspension and centrifuge at $400 \times g$ for $10 \mathrm{~min}$ at $4{ }^{\circ} \mathrm{C}$.

19. Aspirate supernatant and wash again in $1 \mathrm{~mL}$ cold CSM at $400 \times g$ for $10 \mathrm{~min}$ at $4{ }^{\circ} \mathrm{C}$.

20. Partially aspirate supernatant leaving approximately $50 \mathrm{uL}$ of CSM in the tube.

4. Surface Staining

1. Create $100 \mathrm{uL} 2 \mathrm{X}$ antibody master mix (MM) of surface antibodies from Table 2 in CSM.

i. $\quad$ Note: The optimal amount of each metal labeled antibody to add should be determined beforehand.

ii. Add $2 \mathrm{uL}$ each of $160 \mathrm{Gd}$-anti-FITC and 170Er-anti-biotin antibodies to the $\mathrm{MM}$ to detect tetanus and insulin-reactive $\mathrm{B}$ cells, respectively. 
2. Add $50 \mathrm{uL}$ of MM to the depleted sample and $50 \mathrm{uL}$ MM to the enriched sample, such that the final concentration of antibodies per sample is $1 \mathrm{X}$. Vortex briefly and incubate on ice for 15-20 min in dark.

3. Add $1 \mathrm{~mL} \mathrm{CSM}$ to samples and centrifuge at $400 \times g$ for $5 \mathrm{~min}$.

4. Aspirate supernatant and resuspend in $100 \mathrm{uL}$ of $1.6 \%$ PFA. Allow cells to stain in dark for $5 \mathrm{~min}$. Add $1 \mathrm{~mL} \mathrm{CSM}$ and centrifuge at $400 \times g$ for $5 \mathrm{~min}$.

5. While spinning, create an intercalator cocktail: i. $\quad 1 \mathrm{~mL} 1.6 \%$ PFA + $0.5 \mathrm{uL}$ intercalator IR per sample.

6. Add $1 \mathrm{~mL}$ of intercalator solution to each sample and leave at $4{ }^{\circ} \mathrm{C}$ for a minimum of 20 min or up to 1 week.

7. Wash $3 \times$ in MilliQ water.

8. Resuspend in $1 \mathrm{~mL}$ MilliQ water per million cells for running on mass cytometer.

9. Data acquisition and analysis

10. Acquire data on mass cytometer, as previously described [21].

11. Analyze data using third-party analysis software, such as FlowJo (Treestar) or CellEngine [22].

Table 2. Antibody panel.

\begin{tabular}{llll}
\hline Metal Isotopes: & Specificity: & Clone: & Vendor: \\
\hline $\mathbf{1 1 3 C d}$ & CD45 & HI30 & Fluidigm \\
\hline $\mathbf{1 1 5 I n}$ & CD3 & HIT3a & Biolegend \\
\hline $\mathbf{1 4 1 P r}$ & CD22 & HIB22 & Biolegend \\
\hline $\mathbf{1 4 2 N d}$ & CD19 & HIB19 & Fluidigm \\
\hline $\mathbf{1 4 3 N d}$ & CD5 & UCHT2 & Fluidigm \\
\hline $\mathbf{1 4 4 N d}$ & CD69 & FN50 & Fluidigm \\
\hline $\mathbf{1 4 5 N d}$ & CD95 & DX2 & Biolegend \\
\hline $\mathbf{1 4 6 N d}$ & IgD & IA6-2 & Fluidigm \\
\hline $\mathbf{1 4 7 S m}$ & CD20 & 2H7 & Fluidigm \\
\hline $\mathbf{1 4 8 N d}$ & CD38 & HIT2 & Biolegend \\
\hline $\mathbf{1 4 9 S m}$ & CD24 & ML5 & Biolegned \\
\hline $\mathbf{1 5 0 N d}$ & CD86 & IT2.2 & Fluidigm \\
\hline $\mathbf{1 5 1 E u}$ & HLA-DR & G46-6 & Fluidigm \\
\hline $\mathbf{1 5 2 S m}$ & CD36 & $5-271$ & Fluidigm \\
\hline $\mathbf{1 5 3 E u}$ & CD8 & SK1 & Biolegend \\
\hline $\mathbf{1 5 4 S m}$ & CD40 & 5C3 & Biolegend \\
\hline $\mathbf{1 5 5 G d}$ & CD27 & L128 & Fluidigm \\
\hline $\mathbf{1 5 6 G d}$ & CXCR3 & G025H7 & Fluidigm \\
\hline $\mathbf{1 5 8 G d}$ & CD10 & HI10a & Fluidigm \\
\hline & & & \\
\hline
\end{tabular}


Table 2. Cont.

\begin{tabular}{|c|c|c|c|}
\hline Metal Isotopes: & Specificity: & Clone: & Vendor: \\
\hline $159 \mathrm{~Tb}$ & IgKappa & MHK-49 & Biolegend \\
\hline $160 \mathrm{Gd}$ & Anti-FITC & FIT-22 & Fluidigm \\
\hline 161Dy & CD80 & 2D10.4 & Fluidigm \\
\hline 162Dy & CD11c & Bu15 & Fluidigm \\
\hline 163Dy & CD72 & $3 \mathrm{~F} 3$ & Biolegend \\
\hline 164Dy & CD71 & CY1G4 & Biolegend \\
\hline $165 \mathrm{Ho}$ & CXCR5 & $\mathrm{J} 252 \mathrm{D} 4$ & Biolegend \\
\hline $166 \mathrm{Er}$ & CD23 & B3B4 & Biolegend \\
\hline 167Er & IgLambda & $1-155-2$ & Biolegend \\
\hline $168 \mathrm{Er}$ & CD138 & DL-101 & Fluidigm \\
\hline $169 \mathrm{Tm}$ & $\operatorname{IgG}$ & G18-145 & BD Pharmingen \\
\hline $170 \mathrm{Er}$ & Anti-biotin & 1D4-C5 & Fluidigm \\
\hline $171 \mathrm{Yb}$ & PD-L1 & 29E.2A3 & Biolegend \\
\hline $172 \mathrm{Yb}$ & $\operatorname{IgM}$ & MHM-88 & Fluidigm \\
\hline $173 \mathrm{Yb}$ & CD21 & Bu32 & Biolegend \\
\hline $174 \mathrm{Yb}$ & $\mathrm{CD} 4$ & SK3 & Fluidigm \\
\hline 175Lu & CCR4 & L291H4 & Fluidigm \\
\hline $176 \mathrm{Yb}$ & PD-1 & EH12.2H7 & Biolegend \\
\hline 191Ir & Intercalator & & Fluidigm \\
\hline 193Ir & Intercalator & & Fluidigm \\
\hline $195 \mathrm{Pt}$ & Live-dead & & Fluidigm \\
\hline
\end{tabular}

\section{Representative Results}

To demonstrate the method described above, we show representative mass cytometry data obtained using FITC labeled tetanus-toxoid and biotinylated insulin as model antigens to detect and enrich simultaneously for foreign and self-reactive B cells, respectively, from the peripheral blood of a healthy individual. Figure 1 is an overall schematic of the method. Figure 2 shows a comparison of the method using flow cytometry and mass cytometry starting from $\sim 60$ million fresh PBMCs from the same donor that were divided in half and enriched as described above with fluorescently labeled markers substituted for the flow cytometry sample. The donor was last vaccinated with tetanus-toxoid more than 2 years prior to the analysis. Insulin and tetanus-binding B cells were found in frequencies similar to those observed by flow cytometry. Hence, antigen-binding cells are not differentially lost with mass cytometry. However, cell recovery was reduced with mass cytometry compared to flow cytometry, as expected. For the flow cytometry sample, there were approximately 3000 insulin-binding B cells and 2000 tetanus-binding B cells identified, and for the mass cytometry sample, there were approximately 1000 insulin-binding B cells and 500 tetanusbinding B cells identified. Despite the cell loss, antigen-binding B cells can still be easily analyzed for expression of other markers to distinguish varying B cell subpopulations and expression of cell surface markers. 
A.

\section{Depleted}

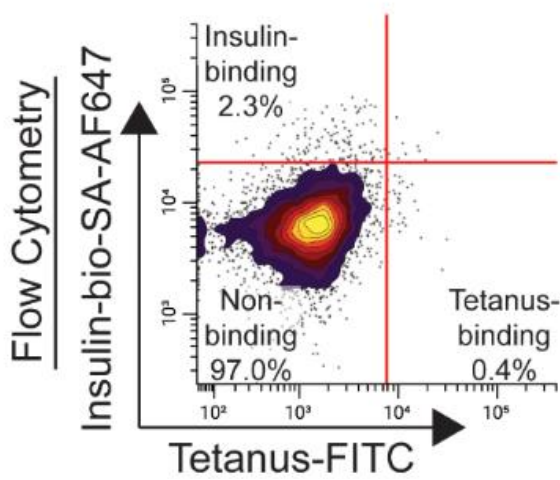

B.

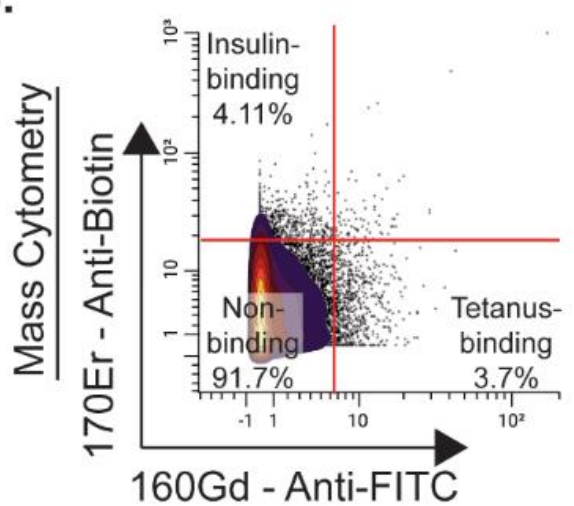

Enriched
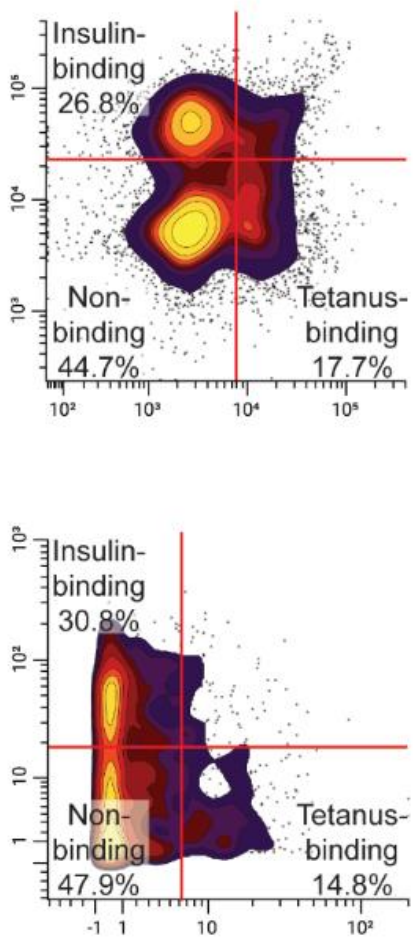

Figure 2. Representative comparison of enrichment of insulin and tetanus-binding B cells using flow cytometry and mass cytometry shows similar binding cell frequencies. Approximately 60 million PBMCs were collected from a single human donor, split in half, with each half enriched for insulin and tetanus-binding B cells as described in this protocol. (A) Representative binding of insulin and tetanusbinding B cells of depleted and enriched fractions using flow cytometry. (B) Representative binding of insulin and tetanus-binding B cells using mass cytometry. For the flow cytometry sample, the addition of fluorescently labeled antibodies (BV421 anti-CD19 and PerCP anti-CD3) and StreptavidinAlexaFluor647 to detect biotinylated insulin bound to the BCR were incubated with the cells in place of metal-labeled antibodies and secondaries. Depleted fractions are negatively enriched cells and enriched fractions are positively enriched cells. Data were analyzed using CellEngine.

Figure 3 demonstrates a representative manual gating strategy used to define major B cell subsets and analysis of cell surface expression of various markers using mass cytometry (Table 2). Figure 3A shows representative gating used to identify insulin, tetanus, and non-binding B cells. We have previously shown that the use of magnetic beads to enrich antigen-binding B cells inevitably results in a number of non-binding bystander cells that get trapped in the matrix [10]. While these impurities can be removed by FACS sorting, non-binding cells represent a good internal negative control to determine differences between non-binding and binding B cells. Figure 3B-D demonstrate representative gating to identify major B cell subjects, including naïve, memory, IgG+ memory, double-negative $(\mathrm{DN})$, anergic $\left(\mathrm{B}_{\mathrm{ND}}\right)$, DN2, plasmablast, and transitional B cells. Once major B cell subpopulations are identified using manual gating strategies, heat maps expressing the mean metal intensities (MMI) of various cell surface molecules can be generated to identify populations that may be highly activated or have altered expressions of varying surface markers (Figure 3E). 

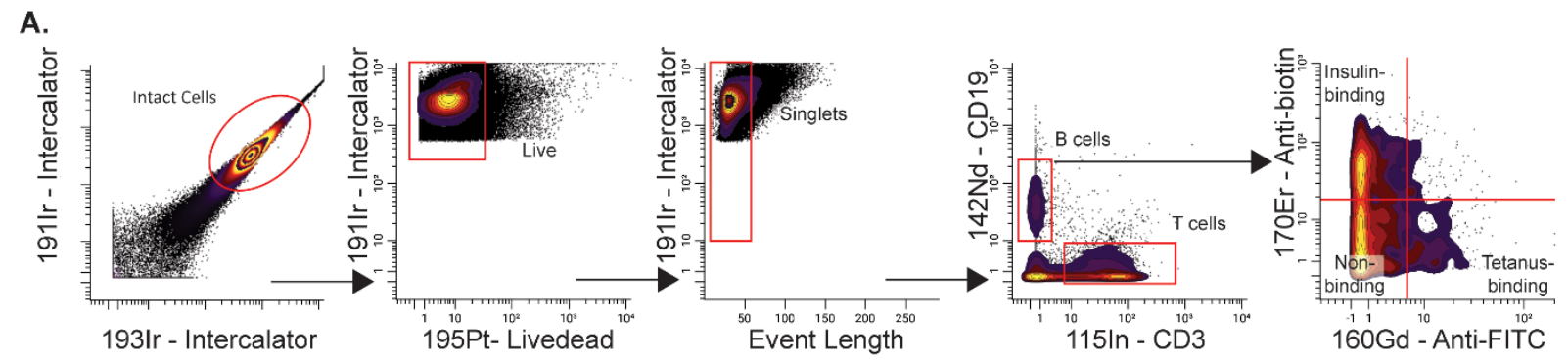

B.

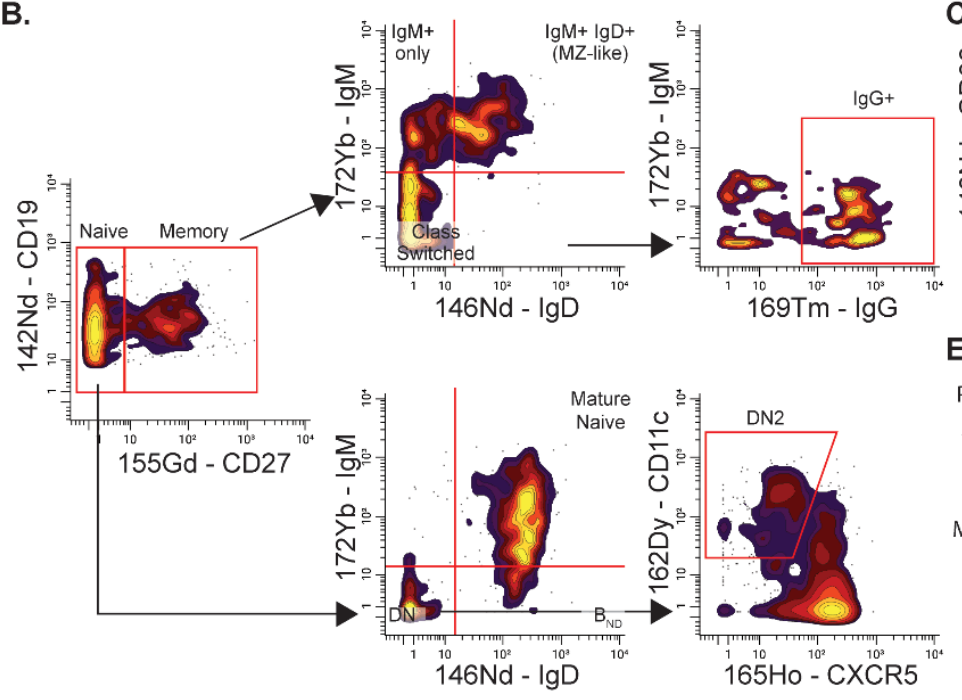

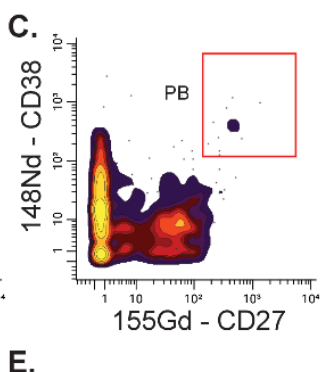
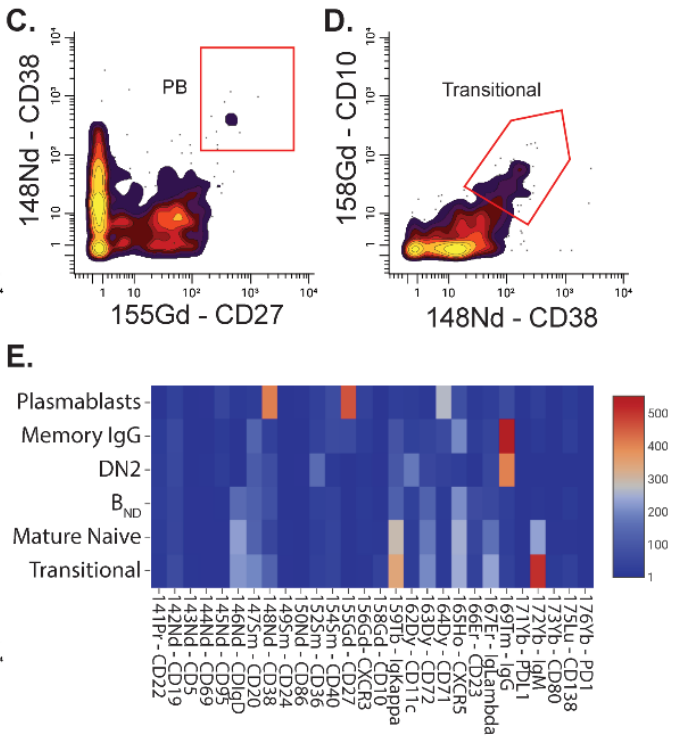

Figure 3. Representative manual gating strategy for identification of antigen-binding B cells and major B cell subsets. (A) Initial gating on intact cells, live cells, singlets, and then B cells to identify insulin and tetanus-binding B cells using mass cytometry. (B) Representative gating to identify major B cell subjects, including naïve (CD27-), memory (CD27+), CS-memory (CD27+ IgM- IgD-), Marginal zone (MZ) memory (CD27+ IgM+ IgD+), IgG+ memory (CD27+ IgG+), mature naïve (CD27- IgM+ IgD+), anergic $\mathrm{B}_{\mathrm{ND}}(\mathrm{CD} 27-\mathrm{IgMlo} \operatorname{IgD}+)$, double-negative (DN) (CD27- IgD-), and DN2 (CD27- IgDCXCR5- CD11c+). Cells were initially gated on CD19+ cells. (C) Representative gating to identify plasmablasts (CD27hi CD38hi). Cells were initially gated on CD19+ cells. (D) Representative gating to identify transitional B cells (CD10hi CD38hi). Cells were initially gating on naïve B cells (CD19+ CD27-). (E) Representative heatmap of various cell surface markers expressed on manually gated B cell subsets. Colors represent raw mean metal intensities (MMI). Data were analyzed by CellEngine.

One of the major advantages of mass cytometry is the large number of parameters that can be analyzed simultaneously, which allows for high dimensional reduction and unbiased monitoring of the immune system. There are many well-written reviews that discuss the various unsupervised clustering algorithms available to analyze mass cytometry data [23-25]. In Figure 4, we show an example of how the unsupervised clustering algorithm, PhenoGraph, can be used to identify various B cell subpopulations using UMAP projections and how the population makeup of insulin, tetanus, and non-binding $B$ cells can be easily visualized and compared. Using this method, we can conclude that in this individual that insulin-binding B cells occur in almost all B cell subpopulations, but particularly in the transitional and naïve (CD27-) subpopulations (populations 1, 3, 4, and 6) and in the $B_{N D}$ anergic population (population 4 ), while tetanus-binding $B$ cells are enriched in the memory subpopulations (populations 2, 8) with few cells in the anergic subset (population 4) (Figure $4 \mathrm{~A}$ ). In addition, we can analyze the differences in surface marker expression of insulin, tetanus, and non-binding B cells by heat mapping, as discussed above (Figure 4B). 
A.

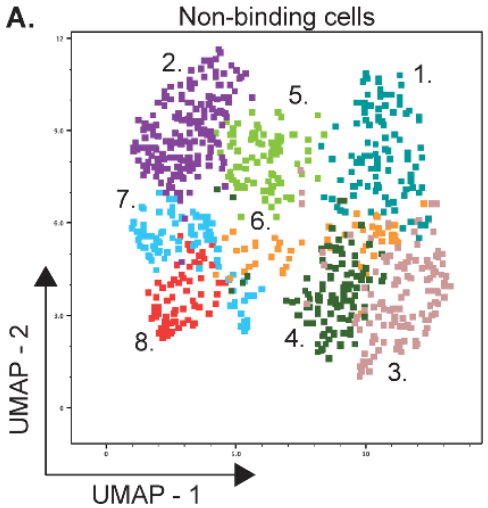

Legend:

1. Transitional (CD10hi, CD38hi)

2. MZ-like memory (CD27+, IgMhi)

3. Mature Naive (CD27-, IgM+, IgD+)

4. $\mathrm{B}_{\mathrm{ND}}$ (CD27-, IgMlo, IgD)

5. Pre-Switch (CD27lo, IgM+, IgD+)

6. DN (CD27-, IgDlo, CXCR5Io, CD11c+)

7. $\lg \mathrm{A}+$ memory (CD27+, $\lg \mathrm{G}=$, $\lg \mathrm{M}$-, $\lg \mathrm{D}$ -

8. IgG+ memory (CD27+ lgG+)
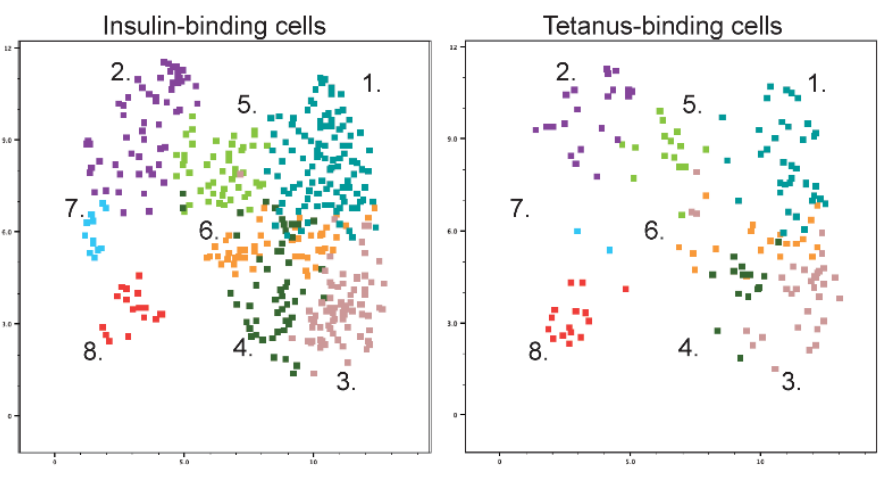

B.

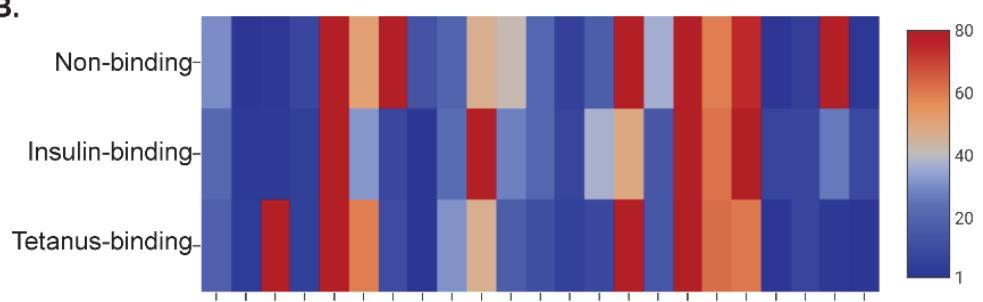

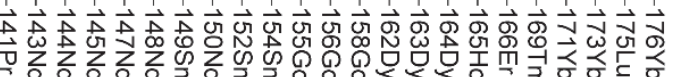

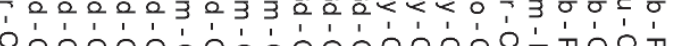

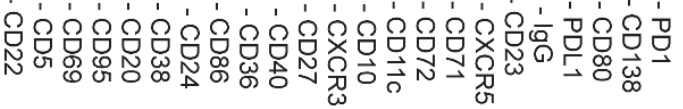

Figure 4. Representative UMAP projections of various B cell subpopulations within the insulin, tetanus, and non-binding B cells demonstrate unique B cell compositions within each antigen-binding B cell subset. (A) Insulin-binding B cells can be found in all major B cell subpopulations, with increased frequency in the transitional and naïve (CD27-) subpopulations (populations 1, 3, 4, and 6). Tetanus-binding B cells are more enriched in the memory subpopulations (populations 2, 8) with few cells in the anergic subset (population 4). UMAP projections were generated using the unsupervised clustering algorithm, PhenoGraph, using the following markers: CD27, CD38, CD10, IgM, IgD, IgG, CXCR5, CD11c, and CD86. Antigen-binding populations were manually gated. (B) Representative heatmap of expression of various cell surface markers expressed on insulin, tetanus, and non-binding B cells. Colors represent raw mean metal intensities (MMI). Heatmap was generated using CellEngine.

\section{Discussion}

Here we demonstrate that enrichment and characterization of antigen-binding B cells can be accomplished using magnetic nanoparticle adsorbents in conjunction with mass cytometry. Moreover, we show that simultaneous identification and analysis of more than one type of antigen-binding B cell is possible within the same sample. We believe this method will greatly inform our understanding of the phenotype and function of the pertinent antigen-reactive B cells during the course of the disease, such as in autoimmunity or cancer, as well as in infection, such as SARS-CoV2. The amount of information that can be gleaned from studying antigen-reactive B cells using mass cytometry data can lead to novel biomarker discoveries that can be used to predict and track the progression of disease and treatment outcomes.

While this method has its advantages over other techniques used to study antigenreactive $B$ cells, such as the ability to analyze many more parameters in one sample than one can achieve using flow cytometry and without the need for compensation or burden of possible autofluorescence, it does come with its own limitations. As discussed above, the low throughput of mass cytometry typically results in fewer cell events compared to flow cytometry, when starting from similar total cell numbers. One way to overcome this limitation is to start with more cells than you typically would for flow cytometry prior to enrichment. In addition, preliminary studies in our own lab have shown that the addition 
of "filler" cells labeled with a unique metal labeled anti-CD45 antibody mixed into the final enriched cell population can increase the number of enriched cells recovered for analysis.

Another limitation of this protocol is the limited availability of cleavable beads. Miltenyi Biotech currently offers anti-biotin, anti-FITC, anti-APC, and anti-PE cleavable beads. Due to the large size of APC and PE (105 kD and $250 \mathrm{kD}$, respectively), we prefer not to label our antigens with these fluorophores, since they potentially contain many antigenic epitopes that could result in increased enrichment of fluorophore-reactive B cells, as previously described [26]. Hence, the use of biotin and FITC, which are much smaller in size (0.244 $\mathrm{kD}$ and $0.389 \mathrm{kD}$, respectively), to label antigens of interest limits the number of antigens that can be concurrently enriched for. Ideally, one could just directly label an antigen with a metal isotope and avoid the use of secondary antibodies for detection, which may be possible depending on the antigen of interest and immune status of the individual. However, from our experience, detection of antigen-reactive B cells from both autoimmune subjects and recently vaccinated individuals requires prior enrichment. In addition, we find the addition of a secondary antibody enhances the signal generated, allowing for better discrimination of binding from non-binding $\mathrm{B}$ cells.

Other general limitations of studying B cells using mass cytometry include (1) the lack of ability to study the repertoire, which is currently best accomplished using singlecell sequencing, (2) the inability to determine the relevant affinity of the BCR for its antigen, which would require knowledge of the variable region sequences, generation of recombinant antibodies, and testing their affinity for their antigen using surface plasmon resonance, and (3) the destruction of the cells in the process, which prevents the ability to conduct downstream functional or in vivo studies. While no method to study antigenreactive $B$ cells has proven to be without its faults, once detection has been optimized using flow cytometry, as previously described [10], this method is quick, relatively simple, and results in reproducible high dimensional data that can be used to deeply probe the immune system on an antigen-specific level.

Author Contributions: Conceptualization, M.J.S.; Writing-original draft preparation, Z.C.S., and M.J.S.; Writing - review and editing, Z.C.S. and M.J.S.; visualization, Z.C.S. and M.J.S.; supervision, M.J.S.; project administration, M.J.S.; funding acquisition, M.J.S. All authors have read and agreed to the published version of the manuscript.

Funding: This research was funded by the University of Colorado School of Medicine Human Immunology \& Immunotherapy Initiative (HI $\left.{ }^{3}\right)$, NIH K01 OD028759 (MJS), NIH DP3 DK110845 (Cambier), and NIH P30 DK116073 (Sussel).

Institutional Review Board Statement: The study was conducted according to the guidelines of the Declaration of Helsinki, and approved by the Institutional Review Board of the University of Colorado Anschutz Medical Campus (01-384, 12-June-2019).

Informed Consent Statement: Informed consent was obtained from all subjects involved in the study.

Acknowledgments: I would like to thank John Cambier for his careful review of the manuscript and his financial contribution.

Conflicts of Interest: The authors declare no conflict of interest.

\section{References}

1. Boonyaratanakornkit, J.; Taylor, J.J. Techniques to Study Antigen-Specific B Cell Responses. Front. Immunol. 2019, $10,1694$. [CrossRef]

2. Haas, W.; Schrader, J.W.; Szenberg, A. A new, simple method for the preparation of lymphocytes bearing specific receptors. Eur. J. Immunol. 1974, 4, 565-570. [CrossRef] [PubMed]

3. De Wildt, R.M.; Steenbakkers, P.G.; Pennings, A.H.; Hoogen, F.H.V.D.; van Venrooij, W.J.; Hoet, R.M. A new method for the analysis and production of monoclonal antibody fragments originating from single human B cells. J. Immunol. Methods 1997, 207, 61-67. [CrossRef]

4. Egeland, T.; Hovdenes, A.; Lea, T.; Egeland, T.; Hovdenes, A.; Lea, T. Positive Selection of Antigen-Specific B Lymphocytes by Means of Immunomagnetic Particles. Scand. J. Immunol. 1988, 27, 439-444. [CrossRef] [PubMed] 
5. Snow, E.C.; Noelle, R.J.; Uhr, J.W.; Vitetta, E.S. Activation of antigen-enriched B cells. II. Role of linked recognition in B cell proliferation to thymus-dependent antigens. J. Immunol. 1983, 130, 614-618. [PubMed]

6. Pinder, C.L.; Kratochvil, S.; Cizmeci, D.; Muir, L.; Guo, Y.; Shattock, R.J.; McKay, P.F. Isolation and Characterization of AntigenSpecific Plasmablasts Using a Novel Flow Cytometry-Based Ig Capture Assay. J. Immunol. 2017, 199, 4180-4188. [CrossRef] [PubMed]

7. Blanchard-Rohner, G.; Galli, G.; Clutterbuck, E.A.; Pollard, A.J. Comparison of a limiting dilution assay and ELISpot for detection of memory B-cells before and after immunisation with a protein-polysaccharide conjugate vaccine in children. J. Immunol. Methods 2010, 358, 46-55. [CrossRef] [PubMed]

8. Doucett, V.P.; Gerhard, W.; Owler, K.; Curry, D.; Brown, L.; Baumgarth, N. Enumeration and characterization of virus-specific B cells by multicolor flow cytometry. J. Immunol. Methods 2005, 303, 40-52. [CrossRef] [PubMed]

9. Saletti, G.; Çuburu, N.; Yang, J.S.; Dey, A.; Czerkinsky, C. Enzyme-linked immunospot assays for direct ex vivo measurement of vaccine-induced human humoral immune responses in blood. Nat. Protoc. 2013, 8, 1073-1087. [CrossRef] [PubMed]

10. Smith, M.J.; Packard, T.A.; O'Neill, S.K.; Hinman, R.M.; Rihanek, M.; Gottlieb, P.A.; Cambier, J.C. Detection and Enrichment of Rare Antigen-specific B Cells for Analysis of Phenotype and Function. J. Vis. Exp. 2017. [CrossRef]

11. Smith, M.J.; Hinman, R.M.; Getahun, A.; Kim, S.; Packard, T.A.; Cambier, J.C. Silencing of high-affinity insulin-reactive B lymphocytes by anergy and impact of the NOD genetic background in mice. Diabetologia 2018, 61, 2621-2632. [CrossRef]

12. Smith, M.J.; Packard, T.A.; O'Neill, S.K.; Dunand, C.J.H.; Huang, M.; Fitzgerald-Miller, L.; Stowell, D.; Hinman, R.M.; Wilson, P.C.; Gottlieb, P.A.; et al. Loss of Anergic B Cells in Prediabetic and New-Onset Type 1 Diabetic Patients. Diabetes 2014, 64, 1703-1712. [CrossRef]

13. Smith, M.J.; Rihanek, M.; Wasserfall, C.; Mathews, C.E.; Atkinson, M.A.; Gottlieb, P.A.; Cambier, J.C. Loss of B-Cell Anergy in Type 1 Diabetes Is Associated With High-Risk HLA and Non-HLA Disease Susceptibility Alleles. Diabetes 2018, 67, 697-703. [CrossRef]

14. Smith, M.J.; Rihanek, M.; Coleman, B.M.; Gottlieb, P.A.; Sarapura, V.D.; Cambier, J.C. Activation of thyroid antigen-reactive B cells in recent onset autoimmune thyroid disease patients. J. Autoimmun. 2018, 89, 82-89. [CrossRef]

15. Leipold, M.D.; Newell, E.; Maecker, H.T. Multiparameter Phenotyping of Human PBMCs Using Mass Cytometry. Methods Mol. Biol. 2015, 1343, 81-95. [CrossRef]

16. Newell, E.; Sigal, N.; Bendall, S.C.; Nolan, G.P.; Davis, M.M. Cytometry by Time-of-Flight Shows Combinatorial Cytokine Expression and Virus-Specific Cell Niches within a Continuum of CD8+ T Cell Phenotypes. Immunity 2012, 36, 142-152. [CrossRef] [PubMed]

17. Gadalla, R.; Noamani, B.; MacLeod, B.L.; Dickson, R.J.; Guo, M.; Xu, W.; Lukhele, S.; Elsaesser, H.J.; Razak, A.R.A.; Hirano, N.; et al. Validation of CyTOF Against Flow Cytometry for Immunological Studies and Monitoring of Human Cancer Clinical Trials. Front. Oncol. 2019, 9, 415. [CrossRef] [PubMed]

18. Lin, D.; Maecker, H.T. Mass Cytometry Assays for Antigen-Specific T Cells Using CyTOF. Adv. Struct. Saf. Stud. 2017, 1678, 37-47. [CrossRef]

19. Newell, E.W.; Sigal, N.; Nair, N.; Kidd, B.A.; Greenberg, H.B.; Davis, M.M. Combinatorial tetramer staining and mass cytometry analysis facilitate T-cell epitope mapping and characterization. Nat. Biotechnol. 2013, 31, 623-629. [CrossRef] [PubMed]

20. Wiedeman, A.; Muir, V.S.; Rosasco, M.G.; DeBerg, H.A.; Presnell, S.; Haas, B.; Dufort, M.J.; Speake, C.; Greenbaum, C.J.; Serti, E.; et al. Autoreactive CD8+ T cell exhaustion distinguishes subjects with slow type 1 diabetes progression. J. Clin. Investig. 2019, 130, 480-490. [CrossRef]

21. Fienberg, H.G.; Simonds, E.F.; Fantl, W.J.; Nolan, G.P.; Bodenmiller, B. A platinum-based covalent viability reagent for single-cell mass cytometry. Cytom. Part A 2012, 81, 467-475. [CrossRef]

22. Leipold, M.D.; Maecker, H.T. Mass Cytometry: Protocol for Daily Tuning and Running Cell Samples on a CyTOF Mass Cytometer. J. Vis. Exp. 2012, 2012, e4398. [CrossRef] [PubMed]

23. Kimball, A.K.; Oko, L.M.; Bullock, B.L.; Nemenoff, R.A.; Van Dyk, L.F.; Clambey, E.T. A Beginner's Guide to Analyzing and Visualizing Mass Cytometry Data. J. Immunol. 2018, 200, 3-22. [CrossRef] [PubMed]

24. Weber, L.M.; Robinson, M.D. Comparison of clustering methods for high-dimensional single-cell flow and mass cytometry data. Cytom. Part A 2016, 89, 1084-1096. [CrossRef] [PubMed]

25. Liu, X.; Song, W.; Wong, B.Y.; Zhang, T.; Yu, S.; Lin, G.N.; Ding, X. A comparison framework and guideline of clustering methods for mass cytometry data. Genome Biol. 2019, 20, 1-18. [CrossRef]

26. Pape, K.A.; Taylor, J.J.; Maul, R.; Gearhart, P.J.; Jenkins, M.K. Different B Cell Populations Mediate Early and Late Memory During an Endogenous Immune Response. Science 2011, 331, 1203-1207. [CrossRef] [PubMed] 